Modeling, Identification and Control, Vol. 40, No. 1, 2019, pp. 11-25, ISSN 1890-1328

\title{
Methods for Experimentally Determining Stiffness of a Multi-Axis Machining Centre
}

\author{
J.F. Røsjordet ${ }^{1}$ G. Hovland ${ }^{1}$ \\ ${ }^{1}$ Department of Engineering Sciences, University of Agder, N-4898 Grimstad, Norway
}

\begin{abstract}
This paper deals with global methods for experimentally determining the static stiffness of multi-axis machining centres. Different devices used for measuring deflection, in specific, are explored, where accuracy and usability are highlighted. The methods were tested on a 3-axis CNC milling machine, 2-axis trunnion table and a 6 -DOF industrial robot.
\end{abstract}

Keywords: Stiffness, Identification, CNC machine, Industrial robot, 3-axis, 5-axis

\section{Introduction}

The overall precision and quality of parts produced with multi-axis machining-centres, strongly relate to the stiffness of the machine. Static stiffness affects dimensional accuracy and dynamic stiffness affects surface finish. The latter also relates to the permissible material removal rate (MRR) of the machine, which is important if high production rates are desirable.

Milling machines in general are known to have a high rigidity due to their high precision requirement. Deflection of the machine tool is therefore small, even with high loads. It is typically measured in the micrometer ( $\mu \mathrm{m})$ scale, which can be difficult to accurately measure in a workshop environment.

One method of measuring static stiffness of the machine is the device presented in Archenti et al. (2012), which is the Loaded Double Ball Bar abbreviated LDBB. The LDBB is essentially a Double Ball Bar constructed as a pneumatic cylinder. A load can then be applied between the spindle and work table and deflection can be measured with an internal length gauge. Another method is presented in, Stejskal et al. (2018), where the stiffness is tested immediately after motion of the machine. One of the conclusions in the paper was that the method with no motion before the measurement yielded much higher stiffness values.
Methods for determining the static stiffness of multiaxis machining-centres, with three measurement techniques, are presented in this paper. With these, the stiffness was measured on a 3 -axis $\mathrm{CNC}$ machining centre, 2-axis trunnion table and a 6-DOF industrial robot, which was equipped with a milling spindle. The specific make and model of the machines are not disclosed in this paper, but the following can be said to describe them. The 3 -axis $\mathrm{CNC}$ and trunnion are regarded as mid-range machines in terms of price and performance. The industrial robot has $>150 \mathrm{~kg}$ payload capability and is similarly priced as the 3 -axis CNC. The robot was equipped with a milling spindle on beforehand and has been used to successfully perform light milling operations in the past.

The paper is organised as follows: Section 2 presents the setup of the experiments that were conducted, Section 3 presents the results found with these methods, and finally Section 4 and section 5 present the discussion and conclusion of the methods and the results.

MATLAB ${ }^{\circledR}$ was used for post-processing of data and to create graphs and figures. Paint.NET ${ }^{\circledR}$ was used to edit pictures and create figures. SolidWorks ${ }^{\circledR}$ was used to create $3 \mathrm{D}$ figures. IRBCAM ${ }^{\circledR}$ was used to generate paths for the 6 -DOF industrial robot. 


\section{Test equipment and setup}

The method used to apply a load to the machine was inspired by the Loaded Double Ball Bar (LDBB) Archenti et al. (2012). This device is characterised by the application of a load between the table and spindle by means of a pneumatic cylinder, and measurement of deflection with an internal length gauge. Such an approach differs from the methods presented in this paper, where the force is directly measured with a force/torque sensor and the deflection is measured externally. The approach more resembles the method presented in Xianming et al. (2016).

\subsection{Stiffness Measurement}

Stiffness is defined by two quantities, which are the applied force and the deflection/deformation of the object when subjected to this force. Presented in this section are the devices used to measure these two quantities. The accuracy of these are presented and an approximation of the total accuracy, in terms of stiffness, is defined.

This paper only deals with linear forces and deflections. The inclusion of torsional forces and deflection would greatly increase the complexity of the test equipment, setup and analysis. It is also recognised that the milling process is dominated by linear forces.

\subsubsection{Force Measurement}

The simplest method of measuring the force exerted by the pneumatic cylinder would be to monitor the internal pressure or have a source with known pressure. However, due to the internal friction of the cylinder, and other sources of error, this was not seen as adequately accurate. Instead, the force was direly measured by a force/torque sensor to minimise the potential error sources. Presented below are the two force/torque sensors that were used and their respective accuracy.

ATI Omega160: The first force/torque sensor that was used, was an ATI Omega160 ATI Industrial Automation (2018b). The sensor was configured with the SI-2500-400 calibration, which gives it the sensing range and accuracy presented in Table 1 . The measurement error is defined as $1.25 \%\left(\mathrm{~F}_{\mathrm{xy}}\right)$ and $0.75 \%\left(\mathrm{~F}_{\mathrm{z}}\right)$ of full scale. Force data from the sensor was gathered with a PCI acquisition card on a dedicated computer. Different versions supports EtherCAT ${ }^{\circledR}$ or other data transfer protocols.

ATI Axia80: The second force/torque sensor that was used, was an ATI Axia80 ATI Industrial Automation (2018a), which is a more compact sensor with lower load capacity. The sensor can use two different calibration profiles with the sensing range and accuracy presented in Table 1. The measurement error is defined as $2 \%$ of full scale in all axes. Force data was transferred over EtherCAT ${ }^{\circledR}$ in real-time to a Beckhoff ${ }^{\circledR}$ $C X 2040$ industrial PC (IPC). Other protocols for data transfer are also available for this sensor.

The main advantage of the Axia80 sensor is that it more closely matches the force levels used in the tests. This means that it yields a better accuracy, even though the Omega160 has better full-scale accuracy. The advantage of EtherCAT ${ }^{\circledR}$ over the PCI acquisition is its ability to provide real-time data transfer.

\begin{tabular}{|c|c|c|}
\hline Model & Fxy (N) & Fz (N) \\
\hline Omega160, Calib. 3 & $2500 \pm 19$ & $6250 \pm 47$ \\
Axia80, Calib. 1 & $200 \pm 4$ & $360 \pm 7.2$ \\
Axia80, Calib. 2 & $500 \pm 10$ & $900 \pm 18$ \\
\hline
\end{tabular}

Table 1: Measuring range and accuracy of ATI force/torque sensors ATI Industrial Automation (2018b)ATI Industrial Automation (2018a).

\subsubsection{Deflection Measurement}

The main challenge for the device used to measure the deflection is the small magnitude that needs to be reliably measured. Some devices are capable of this but are instead limited by practical limitations. Presented below, are the three types of devices that were available for the project and were considered to be most suitable for the task.

Laser tracker: A laser tracker is typically classified as a large scale coordinate measurement machine (CMM) with a high degree of accuracy. It consists of a length measurement device, which typically is an inferometer (IFM), in combination with a 2-axis gimbal and a tracking system.

Two different laser trackers were used during the project, which was a Faro Xi and a Leica AT960. The Faro $X i$ tracker uses an inferometer (IFM) to measure the beam distance with an accuracy of $\pm 2 \mu \mathrm{m}+0.4 \mu \mathrm{m} / \mathrm{m}$ (or $\pm 4 \mu \mathrm{m}+0.8 \mu \mathrm{m} / \mathrm{m}$ Maximum Permissible Error (MPE)) FARO (2009). 3-axis measurement accuracy of the tracker is $\pm 36 \mu \mathrm{m}+6 \mu \mathrm{m} / \mathrm{m}$ MPE. Data was transferred over Ethernet ${ }^{\circledR}$.

The Leica AT960 tracker combines an absolute distance meter (ADM) with the IFM. This makes the device easier to work with, as the tracker can lock back on to the tracker ball if the laser beam is interrupted. The Leica AT960 has higher 3-axis measurement accuracy, with MPE of $\pm 15 \mu \mathrm{m}+6 \mu \mathrm{m} / \mathrm{m}$ Hexagon (2015). However, the tracker was calibrated one month prior to the tests, where the report states that the maximum measurement deviation at $2 \mathrm{~m}$ was $-5.8 \mu \mathrm{m}$ with $0.9 \mu \mathrm{m}$ 
repeatability. Data was transferred from the Leica tracker over EtherCAT ${ }^{\circledR}$ in real-time, to a Beckhoff ${ }^{\circledR}$ $C X 2040$ industrial PC (IPC).

The advantage of using a laser tracker, over the other methods presented in this paper, is that it can take simultaneous 3-axis measurements. This means that the test setup is valid for almost all load directions and machine positions. However, due to the relatively large size of the device, it can not be positioned on most work tables. Therefore, the relative deflection between the tool and table cannot always be measured in a single operation.

The most significant practical advantage of the $L e$ ica over the Faro model used in this work, is that it supports real-time data transfer at $1 \mathrm{kHz}$. Pairing this data with real-time force data essentially provides another dimension to the measurements, which is time.

Digital dial indicator: The most affordable and simple method of measuring the deflection is considered to be using what is commonly known as a dial indicator. In this test, a Mitutoyo $543-251 B$ was used, which is a digital dial indicator with $\pm 3 \mu \mathrm{m}$ absolute accuracy and $1 \mu \mathrm{m}$ resolution.

The advantage of using the dial indicator as a measurement device is that it is a small and compact selfcontained device. It can then be used to measure the deflection at almost any point in the machine with its practical carbide ball tip.

One disadvantage of using a dial indicator is that it requires more manual labour, where the values must be manually read from the display. This also limits the measurements to points where the load can be held constant. In the work presented in this paper, the load cases were no load and full load. Optionally, the data can be gathered with a USB connection, such as the Mitutoyo 06AFM380F. Another disadvantage of the dial indicator method is that only one direction of deflection and one position of the machine is measured at each setup. This disadvantage is in common with the next method to be presented.

Linear differential transformer (LVDT): The third device that was used, was a Linear differential transformer (LVDT). This solution is similar to the method of using a dial indicator, where the difference is mainly that the probing sensor and acquisition electronics are separated. While the structure is similar, LVDT probes and acquisition systems, typically have higher resolution and accuracy than most commercial digital dial indicators. In this test, a Solartron $a x / 1 / s$ LVDT was used, which is listed with a repeatability of $0.15 \mu \mathrm{m}$. Data acquisition was performed with a $A D D I$ DATA MX3700 system for LVDT sensors with 24-bit of resolution. This equates to $1 \times 10^{-4} \mu \mathrm{m}$ theoretical resolution of the reading.
First, the LVDT had to be calibrated together with the acquisition system, since it was not on beforehand. Calibration was performed with C.E. Johansson gauge blocks of grade 0, using the test jig presented in Fig. 1. Grade 0 is, according to ASME B89.1.9-2002, within $\pm 0.12 \mu \mathrm{m}$ of nominal value.

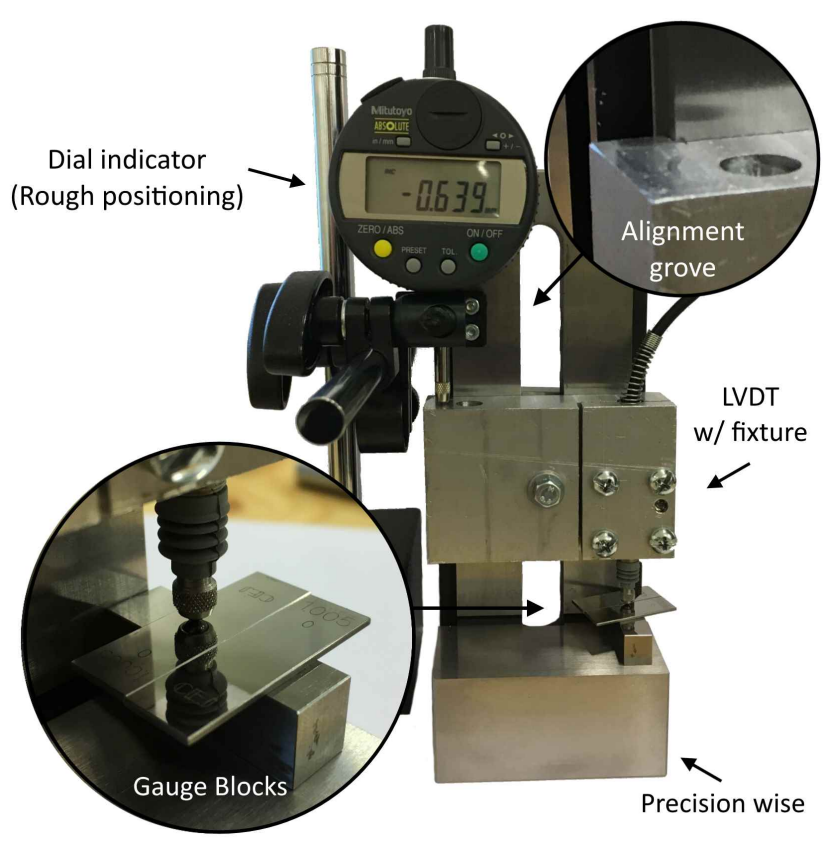

Figure 1: LVDT calibration setup used to measure relative thickness difference of gauge blocks.

First, the calibration routine included with the $A D D I-D A T A$ programs was used. With this method, the accuracy of the LVDT can only be guaranteed with measurements close to its centre position, as it does not account for any nonlinearity. Accuracy and linearity were therefore investigated after the initial calibration by making multiple measurements of different gauge blocks. The measurement error, compared to the nominal thickness of the gauge blocks, is presented in Fig. 2. A spline fit was interpolated between the average value of each of the data point clusters in Fig. 2, such as to approximate values in-between the measurements. Spline fit was used since no known function could be successfully fitted to the data. From the curve fit, it is clear that the LVDT is only approximately linear around the centre position for small probe displacements.

The nonlinearity of the LVDT was then compensated by applying the inverse of this graph to the measurements. Fig. 3 is the residue error of the data points in Fig. 2 after compensation with the inverse of the error curve. 


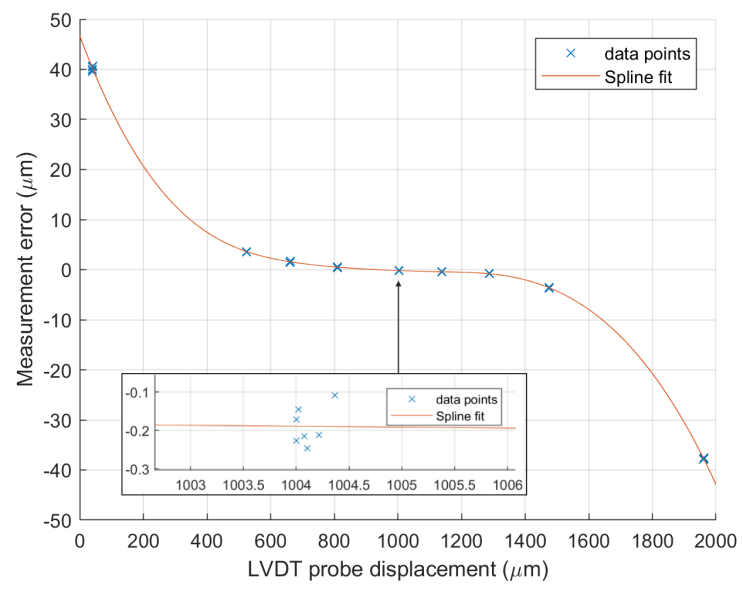

Figure 2: LVDT error at full scale, $\pm 1000 \mu \mathrm{m}$ displacement relative to centre position.

The accuracy of the LVDT after calibration was determined by the following. The gauge blocks are within $\pm 0.12 \mu \mathrm{m}$ of nominal value, however, since the relative measurement between two blocks was taken, the worst case accuracy of $\pm 0.24 \mu \mathrm{m}$ was used. After the nonlinearity compensation, the residual error is within $0.35 \mu \mathrm{m}$ with probe displacement of $\pm 500 \mu \mathrm{m}$ from centre (at $1000 \mathrm{\mu m}$ in Fig. 2). With the above calibration and compensation, the accuracy of the LVDT measurements are estimated to be $\pm 0.59 \mu \mathrm{m}$ for probe displacements of $\pm 500 \mu \mathrm{m}$. In all the results presented in section 3, the LVDT was positioned to within $\pm 100 \mu \mathrm{m}$ of its centre before each measurement.

\subsubsection{Accuracy of measurement}

The stiffness is calculated from both force and deflection and therefore the measurement of both of these dictate the accuracy of the calculated stiffness. Since the two quantities are measured in different units, it was first combined into a common unit less term. First, is the error fraction based on the accuracy of the deflection measurement, $\operatorname{err}_{D}$, which can be calculated by equation 1 . Second, is the error fraction based on the accuracy of the force measurement, $e r r_{F}$, which can be calculated by equation 2 . Force is denoted, $F$, deflection is denoted, $D$, and stiffness is denoted $K$. The two error components are assumed to be uncorrelated and random, where the total error fraction, $\operatorname{err}_{K}$, can be calculated by equation 3. From equation 1 to 3 it is recognised that the overall accuracy is increased in proportion to the load force. The main limitation to the force is the safe load limits of the spindle, which is not always explicitly known.

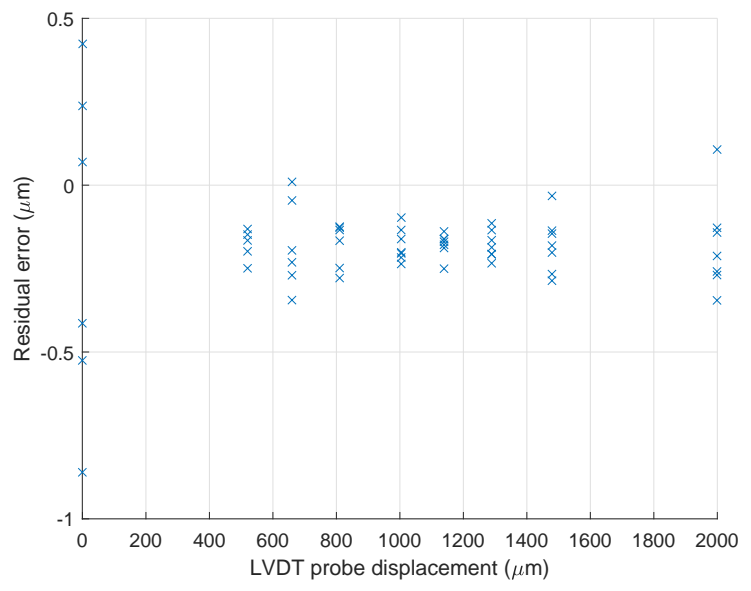

Figure 3: LVDT residue error after nonlinearity compensation.

$$
\begin{gathered}
e r r_{D}=\frac{D_{e r r}}{F / K} \\
e r r_{F}=\frac{F_{e r r}}{F} \\
e r r_{K}=\sqrt{e r r_{D}^{2}+e r r_{F}^{2}}
\end{gathered}
$$

Presented in Table 2 is the numbering system for the test subject and gear combinations used in the experiments. The order that these are presented in represents the order in which they were performed. The two first tests used the Omega160 force/torque sensor, mostly because it was the only suitable sensor that was available at the time. The Axia80 was not acquired until the third test of the 3 -axis CNC. Two different laser trackers were used for the same reason.

Table 3 presents the approximated measurement error as a percentage of the measured stiffness with each of the combinations in Table 2. The stiffness is assumed to be at the upper limit of what the machine was measured to be. An exception is with test 1.1, where the stiffness for one of the measurements must be $>50 \mathrm{~N} / \mu \mathrm{m}$ if the total stiffness is $25 \mathrm{~N} / \mu \mathrm{m}$. Since the measurements in test 1.1 were performed in two operations, the total error, $e r r_{K}$, was also multiplied with $\sqrt{2}$. $5.6 \mu \mathrm{m}$ MPE was used for the FAROXi laser tracker and $5.8 \mu \mathrm{m}$ MPE was used for the Leica AT 960 laser tracker. Force/torque sensor error was based on load in the z-direction, which is the worst case.

Table 3 serves as an indication of the overall stiffness measurement error, where specific numbers for each measurement are presented in section 3. However, the importance of considering the accuracy of the equipment is made clear. 


\begin{tabular}{|c|c|c|c|}
\hline Test & Subject & Sens. F & Sens. D \\
\hline 1.1 & CNC & Omega160 & Faro Xi \\
1.2 & CNC & Omega160 & Mitutoyo 543-251B \\
1.3 & CNC & Axia80 & Solartron ax $/ 1 / \mathrm{s}$ \\
2 & Trunnion & Axia80 & Solartron ax $/ 1 / \mathrm{s}$ \\
3 & Robot & Axia80 & Leica AT960 \\
\hline
\end{tabular}

Table 2: Test numbering for different combinations of measurement devices and test subjects.

\begin{tabular}{|c|c|c|c|c|c|}
\hline Test & $\mathbf{F}$ & $\mathbf{K}$ & $\boldsymbol{e r r}_{\boldsymbol{D}}$ & $\boldsymbol{e r r}_{\boldsymbol{F}}$ & $\boldsymbol{e r}_{\boldsymbol{K}}$ \\
$\boldsymbol{\%}_{\boldsymbol{\%}}$ & $\mathrm{N}$ \\
\hline 1.1 & 275 & 50 & 102 & 17 & 146 \\
1.2 & 275 & 25 & 27 & 17 & 32 \\
1.3 & 275 & 25 & 5 & 7 & 8 \\
2 & 550 & 20 & 2 & 3 & 4 \\
3 & 120 & 1.1 & 5 & 6 & 8 \\
\hline
\end{tabular}

Table 3: Approximated measurement error with different combination of measurement devices. In percents of the measured stiffness.

\subsection{3-Axis CNC}

The 3-axis CNC was the first machine of which the experiments were conducted on. All of the three methods for measuring deflection was tested on this machine with the test setups presented below. The Festo ADN32 pneumatic cylinder and force/torque sensor were mounted in the 3-axis CNC as it is presented in Fig. 4. The cylinder was connected to the spindle and force sensor with two ball joints. These were simply constructed of a steel ball, with a threaded shaft, and a steel cylinder. The measurement devices used in each of the three tests are presented in Table 2.

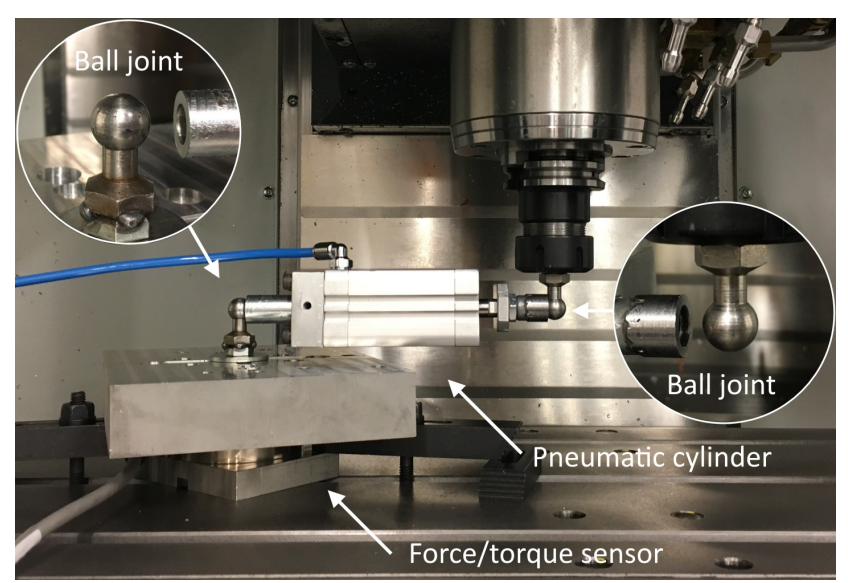

Figure 4: 3-axis CNC: General test setup with pneumatic cylinder and force/torque sensor.
In order to measure the stiffness of the $\mathrm{CNC}$ in different directions, the spindle was relocated to the positions presented in Fig. 5. In the first two tests, the pneumatic cylinder was too long to fit in both the positive and negative $\mathrm{y}$-direction of the workspace. Therefore, the force/torque sensor was positioned $-75 \mathrm{~mm}$ off centre in the $\mathrm{Y}$ direction. The radius of the quarter circle in test 1.1 and 1.2 was $225 \mathrm{~mm}$ and in the full circle of test 1.3, it was $195 \mathrm{~mm}$. The height of the force sensor assembly, from the table surface to the ball centre, was $127 \mathrm{~mm}$ in the first two tests and $108 \mathrm{~mm}$ in the third test.
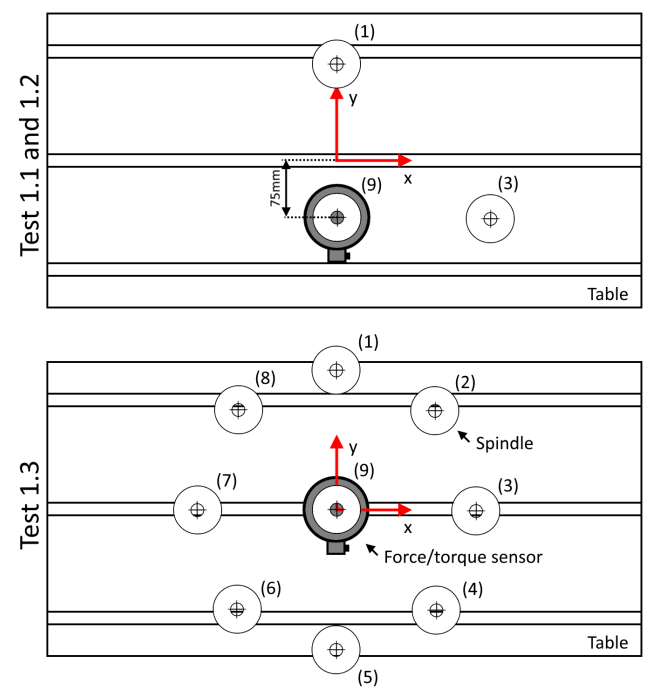

Figure 5: 3-axis CNC: machine position at different measuring points relative to the centre of the table

In the tests featuring the 3 -axis CNC, the stiffness of the machine with the brakes engaged was not considered, unlike the trunnion and industrial robot. This is because the option of manually applying the brakes can not, to the knowledge of the authors, be accessed through the front panel of the controller. However, since the brakes cannot be engaged while the machine is milling, it would not be a realistic case to study, except for identifying the controller stiffness of the servo motors.

Laser tracker: For the first test, the force was measured with the ATI Omega 160 force/torque sensor and the deflection was measured with the FARO Xi laser tracker FARO (2009). Data from both of the sensors were gathered to a dedicated PC, but in different programs which could not be time-synchronised. Since the laser tracker was too large to be placed inside the machine, on the table, the deflection had to be measured in two stages. At the first stage the reflector was placed 
on the table and at the second stage, it was placed on the outside of the spindle housing, as seen in Fig. 6.

However, it is important to notice that, while the stiffness at each of these measurements is presented, it cannot be related to any meaningful property with the known information. This is because, the individual measurements are the deflection relative to the floor, which the machine stands on. Therefore, it is not known what part of the machine that relates to the measured stiffness. When these measurements are added together, this has no influence. Therefore, the total deflection represents the stiffness between measurement points 1 and 2 in Fig. 6 .

To work around the lower 3-axis accuracy of the $F A R O X i$, the laser tracker was positioned such that the beam was aligned with the direction of the measurement that was taken. The accuracy of the tracker measurement was therefore considered to be $5.6 \mu \mathrm{m}$ $\mathrm{MPE}$ at the $\approx 2 \mathrm{~m}$ measuring distance. The estimation in Table 3 was therefore also based on this accuracy. While the laser beam could be well aligned with the $\mathrm{x}$ and y-axis, the z-axis was not as successful.

The initial setup of the laser tracker was reasonably quick to perform and in theory, little changes would have to be made in between each measurement. However, since the tracker had to be moved at each measurement, it essentially was a repetition of the initial setup for each measurement that was taken, which impacted the execution time considerably.

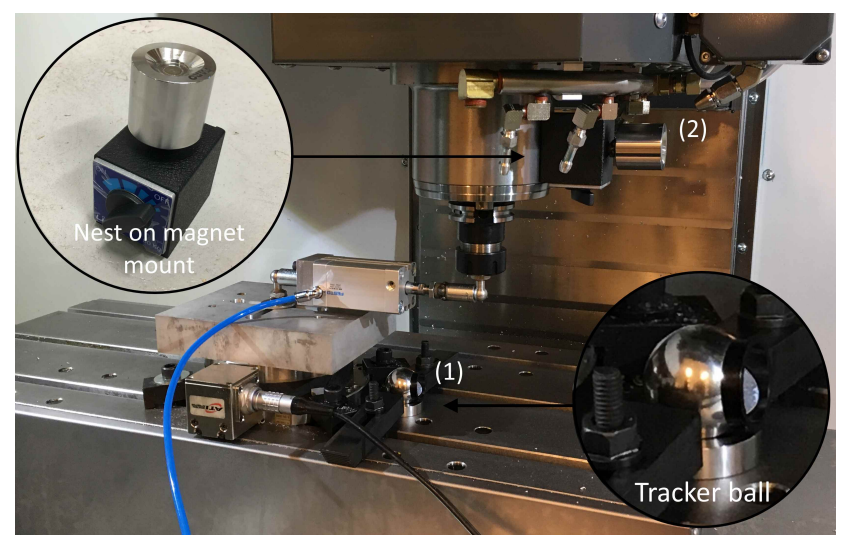

Figure 6: 3-axis CNC, test 1.1: test setup using Faro Xi Laser tracker.

Digital dial indicator: In the second test on the 3axis CNC, the deflection between the table and spindle were measured with a Mitutoyo 543-251B digital dial indicator. The dial indicator was held in place by a magnetic measuring stand, placed on the table of the $\mathrm{CNC}$, as seen in Fig. 7. With measurements in the $\mathrm{x}-\mathrm{y}$ plane, the deflection was measured on the tool holder and in the z-direction, it was measured on the spindle housing. The force that was applied by the pneumatic cylinder was measured with the ATI Omega 160 force/torque sensor. Deflection was read off the display of the indicator and force data was collected on a PC.

The dial indicator test method was more timeconsuming to set up and required additional setup with a change in load direction. However, the amount and cost of the equipment are the lowest of the three methods. Accuracy is increased over the method presented above.

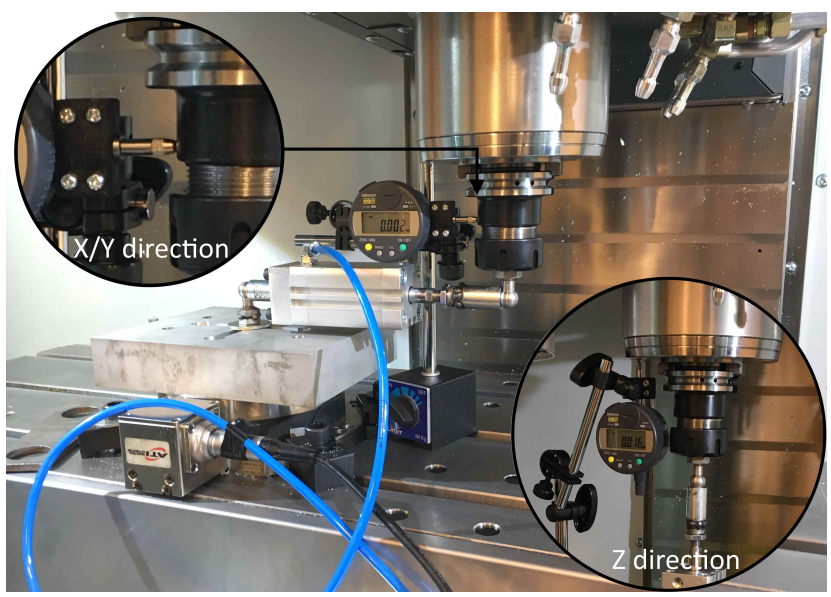

Figure 7: 3-axis CNC, test 1.2: Test setup using Mitutoyo 543-251B digital dial indicator.

LVDT: In the third and last test applied to the 3-axis CNC, the deflection was measured with a Solartron $a x / 1 / s$ LVDT. The force applied to the machine by the pneumatic cylinder was measured with the ATI Axia80 force/torque sensor. This method is similar to the above procedure where the LVDT was held in place by a bracket on a magnetic stand as presented in Fig. 8. All deflection measurements were done on the tool holder. Data from both sensors were gathered with a Beckhoff ${ }^{\circledR} C X 2040$ industrial PC (IPC). Data was logged in two separate programs, but a timestamp was included in each log file such that it could be synchronised in post-processing.

The LVDT method had increased accuracy over the two previously presented methods but required more time to set up than with the laser tracker. Setup time is more or less the same as the dial indicator method with only a slight additional time to connect and configure the acquisition device. Since the data could be synchronised, time spent with post-processing was shorter. The synchronisation also provided another dimension of data, which is time. Like the other methods, it also required additional setup between each point of measurement. 


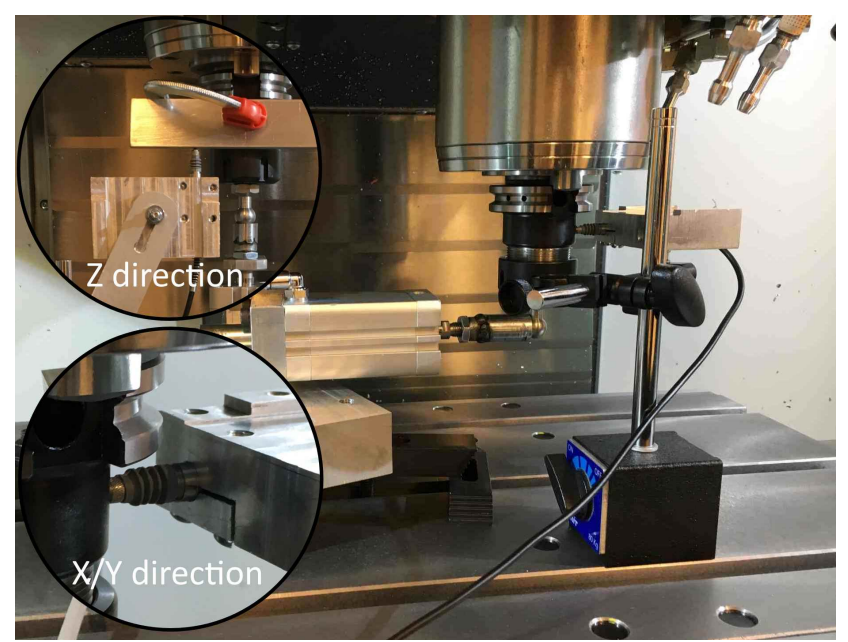

Figure 8: 3-axis CNC, test 1.3: Test setup using Solartron ax/1/s LVDT.

\subsection{2-Axis Trunnion}

While it was first of interest to identify the stiffness of the $\mathrm{CNC}$ as a 5 -axis machine, including the 2-axis trunnion table, these were tested separately. The load imposed on the trunnion could then be increased with less concern of overloading any spindle bearings. Also, the CNC that the 2-axis table was connected to, was not identical to the machine that the other tests were performed on.

The setup presented in Fig. 9 was then used to apply a load to the table, where the spindle was essentially replaced with a jig that holds the force sensor in place. The pneumatic cylinder was then connected between the force sensor and another ball joint mounted to the table with a lathe chuck. Deflection was measured on a plate that was held by a stand which was mounted to the base of the lathe chuck. Thus, the stiffness of the lathe chuck and bracket would not affect the measurements. Similarly to the test with the CNC, the LVDT was held in place by a magnetic stand. The stand was placed on a bracket that was bolted right next to the mounting points of the trunnion.

The 2-axis trunnion was tested with loads in $\mathrm{x}, \mathrm{y}$ and z-direction, as presented in Fig. 10 at the points presented in Table 4. Coordinates are relative to the centre of the face of the table, which is where the A and B-axis ( $4^{\text {th }}$ and $5^{\text {th }}$-axis) coincide.

If 5-axis indexed machining is performed, the brakes of the 2-axis trunnion are typically engaged in order to increase rigidity. The effect of the brakes was therefore investigated by repeating the tests with different combinations of brakes on the $\mathrm{A}$ and B-axis.

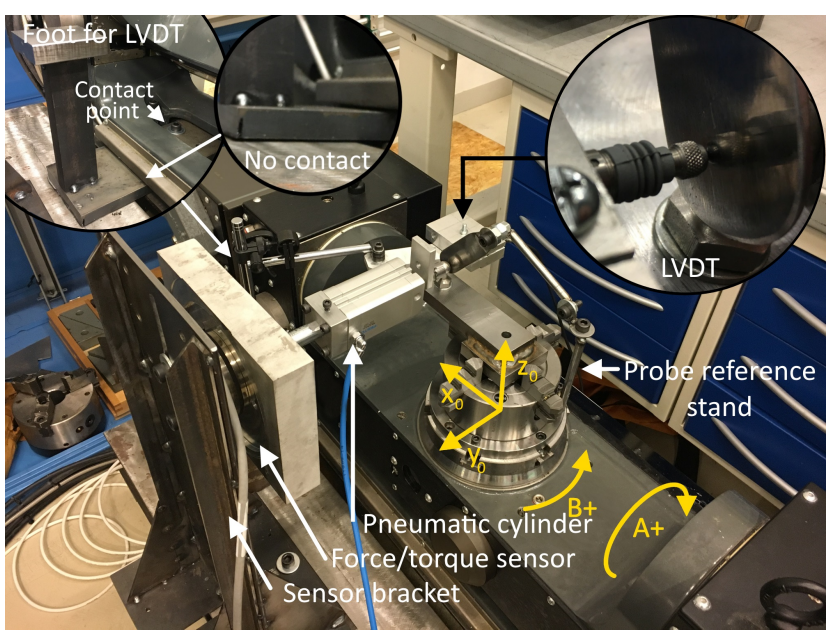

Figure 9: 2-axis trunnion: test setup using LVDT, pneumatic cylinder and force/torque sensor. in Position 4.

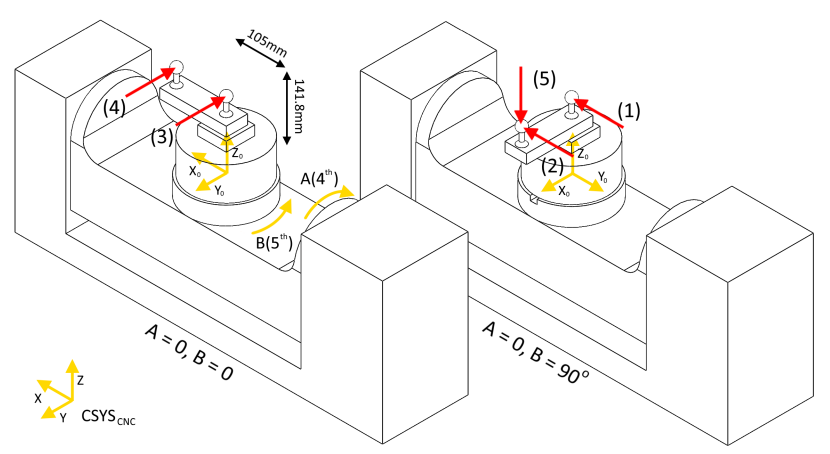

Figure 10: 2-axis trunnion: direction and placement of load.

\subsection{6-DOF Industrial Robot}

The last test was performed on a 6 -DOF industrial robot, fitted with a milling spindle, with the test setup presented in Fig. 11. The force was measured with a ATI Axia80 force/torque sensor mounted to the work table. The load limits of the spindle were unclear as well as a lower stiffness was expected of the robot. Therefore, a lower force was applied to the robot compared to the 3-axis CNC. To maintain the accuracy of the force measurement, the sensor was then configured with calibration 1 (see Table. 1).

At the time of the test, the Leica AT960 was available and was therefore used. This laser tracker has the advantage of support for real-time data transfer as well as better accuracy than the older model of the Faro Xi, which was available. 


\begin{tabular}{|c|c|c|}
\hline $\mathbf{P .}$ & $\mathbf{x}, \mathbf{y}, \mathbf{z}, \mathbf{A}, \mathbf{B}$ & $\mathbf{D .}$ \\
\hline 1 & $0,0,141.8,0,0$ & $x$ \\
2 & $105,0,141.8,0,90$ & $x$ \\
3 & $0,0,141.8,0,0$ & $y$ \\
4 & $105,0,141.8,0,0$ & $y$ \\
5 & $105,0,141.8,0,90$ & $z$ \\
\hline
\end{tabular}

Table 4: 2-axis trunnion: load positions relative to centre of table surface (see fig. 10). Coordinates follow the rotation of the $A / B$-axis.

The measurement reflector was mounted to the body of the spindle with the bracket shown in Fig 11. The reflector was positioned such that it was in line with the Tool Centre Point (TCP) in the $\mathrm{x}$-axis at home position (at zero tool rotation around the z-axis). Both the Leica AT960 and ATI Axia80 supported EtherCAT ${ }^{\circledR}$, which allowed the data to be gathered to a Beckhoff ${ }^{\circledR}$ IPC in real-time. All of the data could then be synchronised and saved to a single file, which reduced the time required for post-processing considerably.

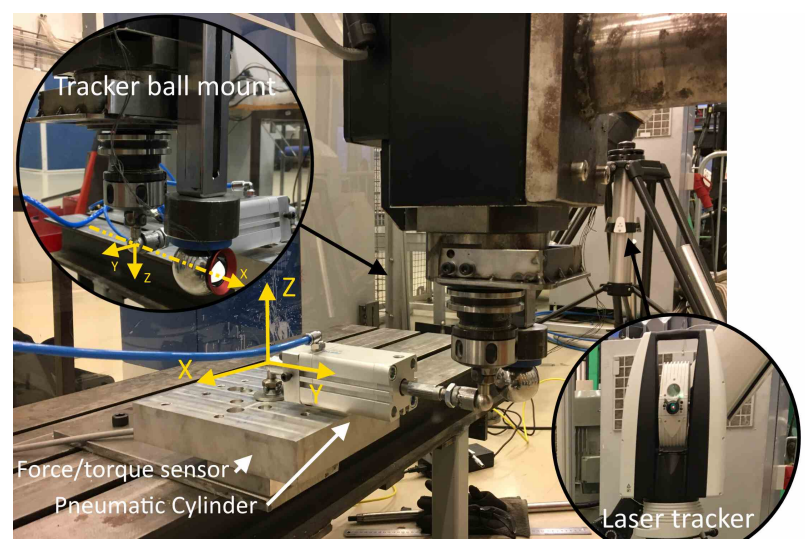

Figure 11: 6-DOF industrial robot: test setup using pneumatic cylinder, force sensor and laser tracker.

The robot was first tested at the points presented in Fig. 12, which are positioned with 45 degrees increment on a $220 \mathrm{~mm}$ radius sphere. The radius of the sphere were later extended to $525 \mathrm{~mm}$ and $810 \mathrm{~mm}$ by adding extensions to the same cylinder. The largest radius could not be tested in the y-direction, since it did not fit within the workspace of the robot and robot cell. The orientation of the robot, relative to the test points, are presented in Fig. 13.

The stiffness of the robot was in this case also tested with the brakes engaged. Like the 3 -axis CNC, it is not a realistic scenario in terms of the milling process. It does, however, help to identify the effect that the servo stiffness has on the robot.

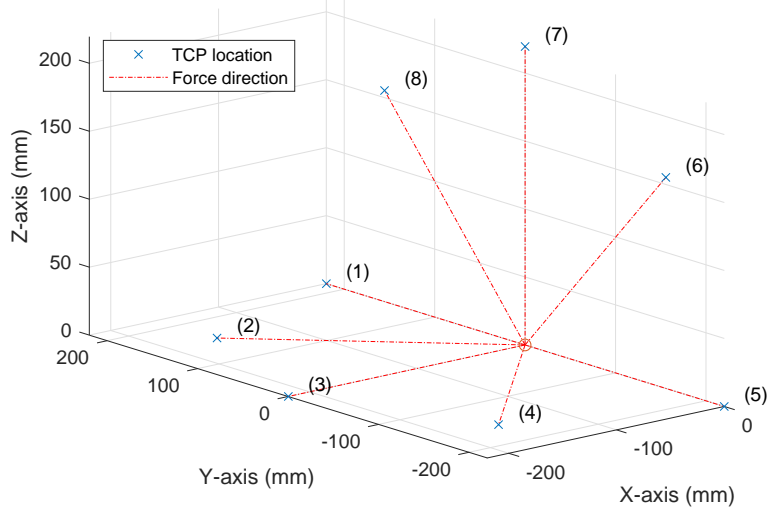

Figure 12: 6-DOF Industrial Robot: TCP location during tests with $220 \mathrm{~mm}$ pneumatic cylinder.

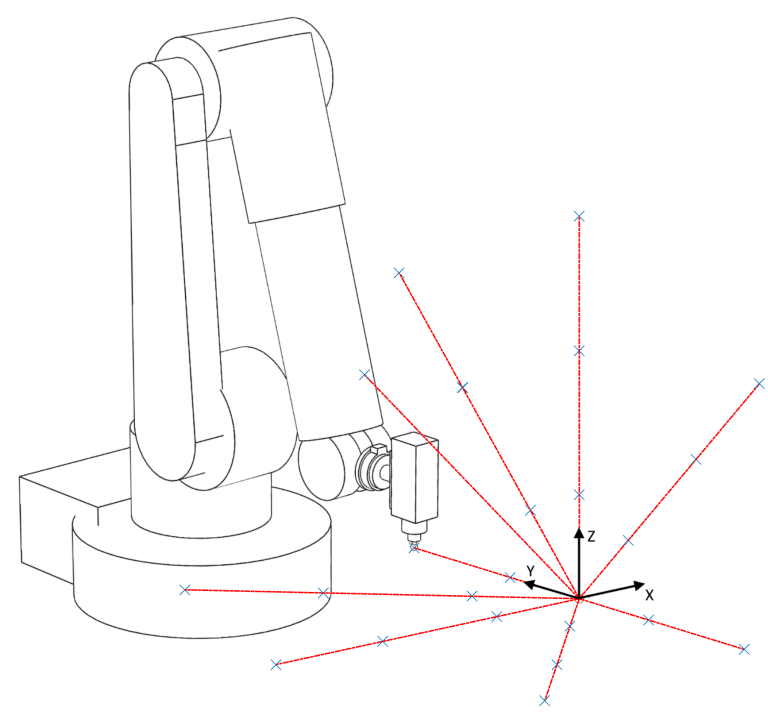

Figure 13: 6-DOF Industrial Robot: position of robot relative to centre of ball joint connected to force sensor.

An ATI Omega160 force/torque sensor was already mounted between the spindle bracket and the robot, but was not used for the following tests. The force sensor was not removed before the measurements were made, since it is typically used when the robot is used to perform milling tasks. Also, the stiffness of the sensor is known as the following ATI Industrial Automation (2018b): $K_{s, x}=K_{s, y}=7 \cdot 10^{7} \mathrm{~N} / \mathrm{m}$, $K_{s, z}=1.2 \cdot 10^{8} \mathrm{~N} / \mathrm{m}, K_{\theta, x}=K_{\theta, y}=3.3 \cdot 10^{5} \mathrm{Nm} / \mathrm{rad}$ and $K_{\theta, z}=5.2 \cdot 10^{5} \mathrm{Nm} / \mathrm{rad}$. Stiffness of the sensor in respect to the TCP can then be calculated from equation 4 to equation 6 . Tool parameters $L_{y}$ and $L_{z}$ are presented in Fig. 14. 


$$
\begin{array}{r}
K_{x}=\left(\frac{1}{K_{s, x}}+\frac{L_{z}^{2}}{K_{\theta, z}}+\frac{L_{y}^{2}}{K_{\theta, y}}\right)^{-1} \approx 2.9 \mathrm{~N} / \mu m \\
K_{y}=\left(\frac{1}{K_{s, z}}+\frac{L_{z}^{2}}{K_{\theta, x}}\right)^{-1} \approx 5.4 \mathrm{~N} / \mu \mathrm{m} \\
K_{z}=\left(\frac{1}{K_{s, y}}+\frac{L_{y}^{2}}{K_{\theta, x}}\right)^{-1} \approx 4.3 \mathrm{~N} / \mu \mathrm{m}
\end{array}
$$

The stiffness values of the force sensor are considerably higher than the robot stiffness and hence are neglected in the following analysis.

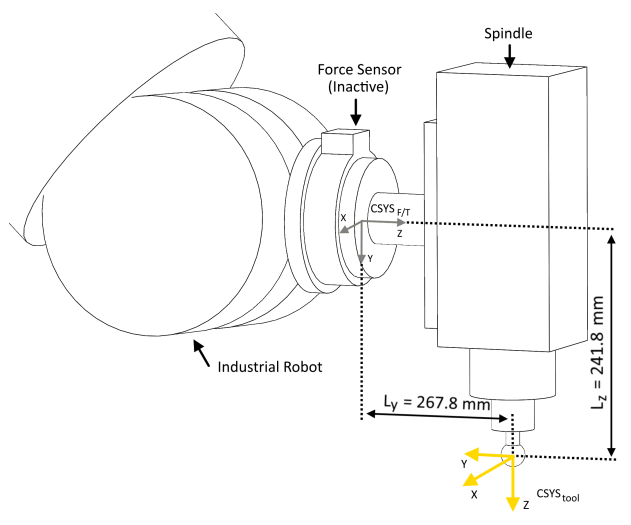

Figure 14: 6-DOF industrial robot: tool offset from the inactive ATI Omega160 force/torque sensor.

\section{Test Results}

Presented in this section are the results that were obtained from the experiments performed with the methods described above.

\subsection{3-Axis CNC}

The results obtained with the measurement of stiffness on the 3 -axis CNC machine are presented below. Three different methods were used to test this, which are presented in the same order as the methods were in the previous section.

Laser tracker: First are the results obtained with the combination of the FAROXi laser tracker and the ATI Omega160 force/torque sensor. The force was applied from $\approx 0 \mathrm{~N}$ to $275 \mathrm{~N}$ in $\approx 13 \mathrm{~s}$. Average measured stiffness, $K_{a v g, 1}$ and $K_{a v g, 2}$, from ten repeated tests at the two positions of the tracker ball are presented in Table 5. See Fig. 6 for position of measurement 1 and 2. Total stiffness was then calculated by $K_{\text {avg }}=\left(K_{\text {avg }, 1}^{-1}+K_{\text {avg }, 2}^{-1}\right)^{-1}$. Precision is presented as standard deviation (SD.), and the measurement error

\begin{tabular}{|c|c|c|c|c|c|c|}
\hline P. & D. & & $\begin{array}{c}\mathbf{K}_{\text {avg, }} \\
\mathrm{N} / \mu \mathrm{m}\end{array}$ & $\begin{array}{c}\text { SD. } \\
\%\end{array}$ & $\begin{array}{c}\text { Err. } \\
\%\end{array}$ & $\begin{array}{l}\mathbf{K}_{\text {avg }} \\
\mathrm{N} / \mu \mathrm{m}\end{array}$ \\
\hline \multirow{2}{*}{1} & \multirow{2}{*}{$y$} & 1 & 70.5 & 10.4 & 131.7 & \multirow{2}{*}{37.6} \\
\hline & & 2 & 80.4 & 8.1 & 150.2 & \\
\hline \multirow{2}{*}{3} & \multirow{2}{*}{$x$} & 1 & 77.1 & 6.7 & 144.0 & \multirow{2}{*}{26.2} \\
\hline & & 2 & 39.6 & 1.4 & 74.2 & \\
\hline \multirow{2}{*}{9} & \multirow{2}{*}{$z$} & 1 & 155.7 & 10.3 & 291.1 & \multirow{2}{*}{26.4} \\
\hline & & 2 & 31.8 & 3.8 & 61.5 & \\
\hline
\end{tabular}
(Err.) was approximated from equation 3. Both are percentages of the measured stiffness.

Table 5: 3-axis CNC, test 1.1: average stiffness at measurements point 1 and 2 and total stiffness. At different positions (P.) and directions (D.).

Dial indicator: Second, are the results that were obtained with the combination of the Mitutoyo 543-251B digital dial indicator and ATI Omega160 force/torque sensor. The force was applied from $\approx 0 \mathrm{~N}$ to $275 \mathrm{~N}$ in $\approx 13 \mathrm{~s}$. Average measured stiffness are presented in Table 6 . Stiffness, $K_{\text {avg }}$ was calculated from ten repeated tests for each direction, $\mathrm{x}, \mathrm{y}$ and $\mathrm{z}$.

\begin{tabular}{|cc|c|c|c|}
\hline P. & D. & $\begin{array}{c}\mathbf{K}_{\text {avg }} \\
\text { N/ } \mu \mathrm{m}\end{array}$ & $\begin{array}{c}\text { SD. } \\
\mathbf{\%}\end{array}$ & $\begin{array}{c}\text { Err. } \\
\mathbf{\%}\end{array}$ \\
\hline 1 & $y$ & 38.4 & 2.2 & 41.8 \\
3 & $x$ & 21.9 & 0.9 & 24.8 \\
9 & $z$ & 103.2 & 27.5 & 111.2 \\
\hline
\end{tabular}

Table 6: 3-axis CNC, test 1.2: average stiffness from measurements. At different positions (P.) and directions (D.).

LVDT: Finally, the results obtained with the Solartron $a x / 1 / s$ LVDT in combination with the ATI Axia80 force/torque sensor, are presented. It was, in this case, possible to continuously measure both force and deflection. The force was then applied in cyclic periods, with the characteristic shape presented in Fig. 15. Force versus deflection graphs, such as the one presented in Fig. 17, could then be generated. The measurements were made with 20 consecutive load cycles.

With the assumption of linearity, the stiffness was then approximated by fitting a line to the data using the least square method. The regression was not performed on the whole data set, but rather on each of the load cycles. The average stiffness of the 20 load cycles was then calculated. An example of the least square fit to one of the load cycles is presented in Fig. 17.

Stiffness in all directions in Fig. 5 is presented in Table 7. Stiffness is also presented as a polar plot in Fig. 16 for the test points in the xy-plane. 


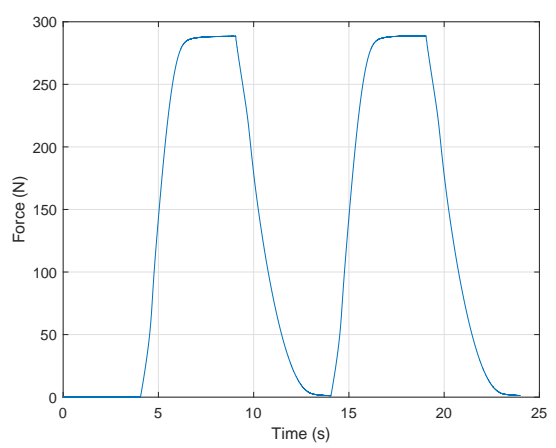

Figure 15: 3-axis CNC, test 1.3: two force application cycles.

\begin{tabular}{|cc|ccc|}
\hline P. & D. & $\begin{array}{c}\mathbf{K}_{\text {avg }} \\
\text { N/um }\end{array}$ & $\begin{array}{c}\text { SD. } \\
\text { \% }\end{array}$ & $\begin{array}{c}\text { Err. } \\
\text { \% }\end{array}$ \\
\hline 1 & $y$ & 18.4 & 0.3 & 5.1 \\
2 & $x y_{45^{\circ}}$ & 18.1 & 0.2 & 4.8 \\
3 & $x$ & 15.8 & 0.4 & 4.5 \\
4 & $x y_{45^{\circ}}$ & 16.6 & 0.2 & 5.0 \\
5 & $y$ & 21.1 & 0.1 & 5.4 \\
6 & $x y_{45^{\circ}}$ & 18.5 & 0.2 & 4.9 \\
7 & $x$ & 14.8 & 0.1 & 4.5 \\
8 & $x y_{45^{\circ}}$ & 16.3 & 0.1 & 5.0 \\
9 & $z$ & 24.7 & 0.2 & 6.1 \\
\hline
\end{tabular}

Table 7: 3-axis CNC, test 1.3: average stiffness at different positions (P.) and directions (D.).

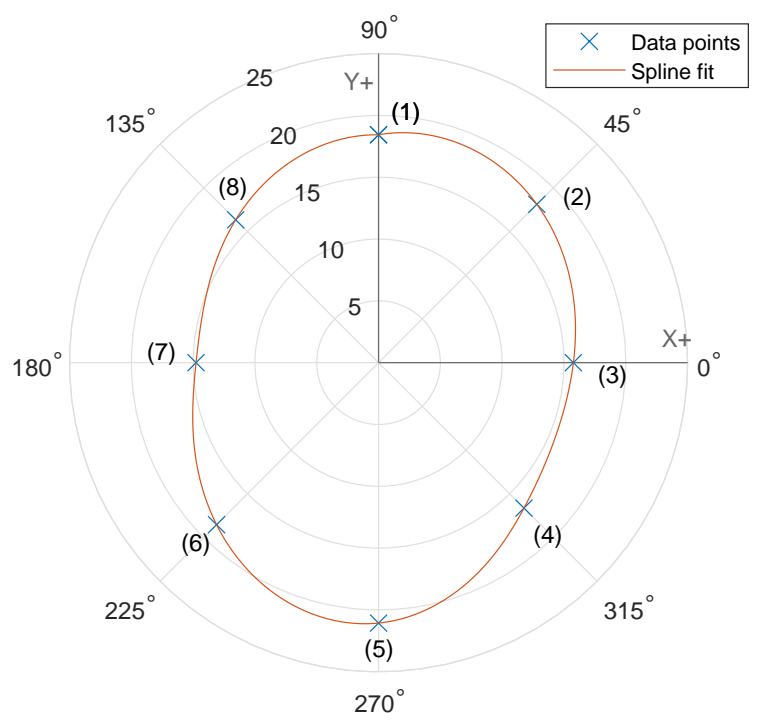

Figure 16: 3-axis CNC, test 1.3: polar plot with average stiffness in the xy-plane at different

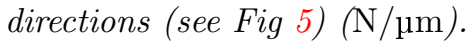
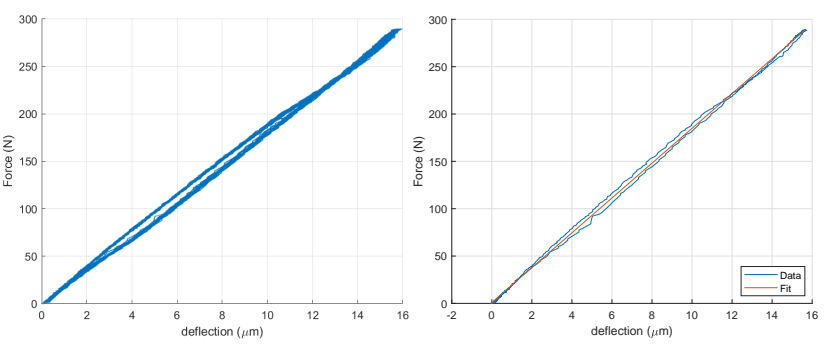

Figure 17: 3-axis CNC, test 1.3: force versus deflection. Test position 1 in Fig. 5. All load cycles $(L)$, single load cycle with least square fit $(R)$.

\subsection{2-Axis Trunnion}

The results obtained from the 2-axis trunnion, are presented below. The load cycles presented in Fig. 18 were applied with the pneumatic cylinder. The measurements were performed with different combinations of brakes on the rotary axes. Force versus deflection graphs such as the two presented in Fig. 20 were then obtained. The two graphs represent the exact same setup where the only difference is that one was performed with the servos active and the other with the brakes engaged. The measurements indicate that there is an increased level of hysteresis in the system when the servos are active. It was also observed that the first load cycle gave the deflection presented in Fig. 19. The trend of the deflection is thought to originate from the control system of the servo motors, where it compensates against the applied force or deflection. The deflection settled to a constant mean value after about two load cycles and did not re-appear before axis was moved. It also did not appear in a consistent manner. Measurements which had this trend was therefore discarded before a new one was taken.

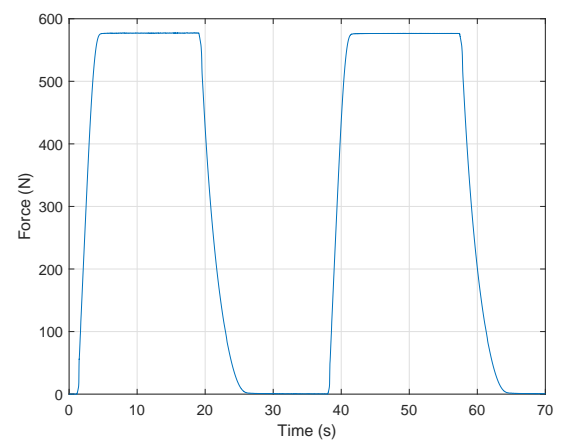

Figure 18: 2-axis trunnion: two force application cycles. 


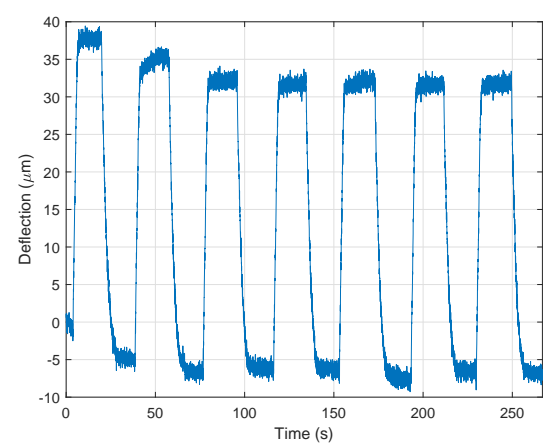

Figure 19: 2-axis trunnion: deflection measurement at first load application (position 3) (R).
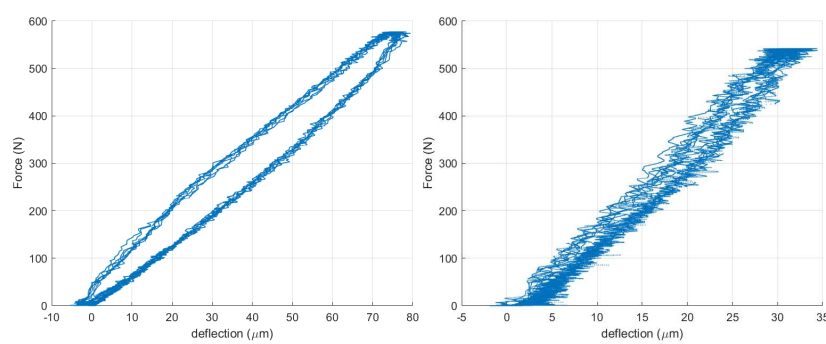

Figure 20: 2-axis trunnion: force versus deflection example with six load cycles. Load in y-dir at position 4. With active servos (L), With active Brakes (R).

The stiffness was again approximated by the inverse of the slope of a straight line fitted to the data of one cycle. Total stiffness was then found from the average of these with above 14 cycles for all tests. Example of the fit to the data is presented in Fig. 21.

Calculated stiffness from all measurements with the brake disengaged and the servos active, are presented in Table 8. Precision is presented as the standard deviation (SD.) and the measurement error (Err.) was approximated from equation 3 . Stiffness along x-direction with load perpendicular to the B-axis was greater than what could be measured consistently and is therefore marked as N/M (not measurable).

Stiffness with different combinations of brake engagement on the A and B-axis is presented in Table 9. Except for the cases where no torque load was applied to the axis (no load point offset), which is labelled N/A. From the measurements, it is clear that while the gain is not always as large, the brakes does increase the stiffness. Estimated error (Err.) and standard deviation (SD.) is not presented here.

The values in Table 8 are presented as linear stiffness and is therefore only valid for the positions and
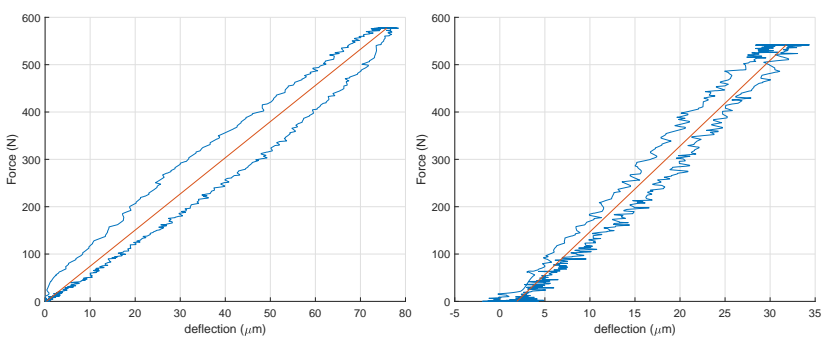

Figure 21: 2-axis trunnion: least square fit on data in a single load cycle. Load in y-dir, at position 4. With active servos $(L)$, With active Brakes (R).

\begin{tabular}{|ll|ccc|}
\hline P. & D. & $\begin{array}{c}\mathbf{K}_{\text {avg }} \\
\mathrm{N} / \mu \mathrm{m}\end{array}$ & $\begin{array}{c}\text { SD. } \\
\mathbf{\%}\end{array}$ & $\begin{array}{c}\text { Err. } \\
\mathbf{\%}\end{array}$ \\
\hline 1 & $x$ & $\mathrm{~N} / \mathrm{M}$ & $\mathrm{N} / \mathrm{M}$ & $\mathrm{N} / \mathrm{M}$ \\
2 & $x$ & 18.8 & 4.3 & 3.9 \\
3 & $y$ & 14.8 & 3.3 & 3.6 \\
4 & $y$ & 7.4 & 1.5 & 3.2 \\
5 & $z$ & 53.2 & 7.0 & 6.5 \\
\hline
\end{tabular}

Table 8: 2-Axis trunnion: average stiffness and standard deviation from test measurements at different positions and directions. Active servos.

\begin{tabular}{|c|c|c|c|c|c|}
\hline P. & D. & $\begin{array}{c}\text { No } \\
\text { N/pm }\end{array}$ & $\begin{array}{c}\mathbf{A} \\
\mathrm{N} / \mathrm{\mu m}\end{array}$ & $\begin{array}{c}\text { B } \\
\mathrm{N} / \mu \mathrm{m}\end{array}$ & $\begin{array}{l}\mathbf{A}+\mathbf{B} \\
\mathrm{N} / \mu \mathrm{m}\end{array}$ \\
\hline 1 & $x$ & $\mathrm{~N} / \mathrm{M}$ & $\mathrm{N} / \mathrm{A}$ & $\mathrm{N} / \mathrm{A}$ & $\mathrm{N} / \mathrm{A}$ \\
\hline 2 & $x$ & 18.8 & $\mathrm{~N} / \mathrm{A}$ & 19.9 & $\mathrm{~N} / \mathrm{M}$ \\
\hline 3 & $y$ & 14.8 & $\mathrm{~N} / \mathrm{A}$ & 16.5 & $\mathrm{~N} / \mathrm{A}$ \\
\hline 4 & $y$ & 7.4 & 7.9 & 15.2 & 17.8 \\
\hline 5 & $z$ & 53.2 & 68.8 & $\mathrm{~N} / \mathrm{A}$ & $\mathrm{N} / \mathrm{A}$ \\
\hline
\end{tabular}

Table 9: 2-Axis trunnion: average stiffness without brake (No) and with $A$ and $B$-axis brake combinations.

directions presented in Table 4 . However, to a certain degree of accuracy, the trunnion can be represented as two rotational springs. By this approximation, the Aaxis stiffness is $297000 \mathrm{Nm} / \mathrm{rad}$ in pos. 9 (see Fig. 10) and the B-axis stiffness is $197000 \mathrm{Nm} / \mathrm{rad}$ in pos. 8 . Using these values to approximate the linear stiffness of pos. 10 , a value of $8.3 \mathrm{~N} / \mu \mathrm{m}$ is found, which deviates $\approx 11 \%$ off the actually measured stiffness. While the simplified model gives a reasonably accurate estimation for when the load is in the y-direction, it gives a bad estimate for the stiffness in the $\mathrm{z}$-direction at $27.0 \mathrm{~N} / \mu \mathrm{m}$ ( $\approx 50 \%$ error). The bad estimate is presumably due to the fact that the load direction is different. Then the load case of the trunnion structure is changed, which makes the above approximation inaccurate. 


\subsection{5-Axis CNC Stiffness (CNC+Trunnion)}

To get an idea of how much the 2-axis trunnion affects the stiffness of the CNC, the results from test 1.3 and 2 were combined. The combination of the results is not entirely accurate, where if the trunnion is mounted to the CNC, the working surface is raised. The leverage that the load has on the table of the 3 -axis $\mathrm{CNC}$ is then increased, which reduces the perceived stiffness.

Presented in Table 10 is the combined stiffness in $\mathrm{x}$, $\mathrm{y}$ and $\mathrm{z}$-direction. The two stiffness components were considered as springs in series where the total was approximated as, $K_{5-a x}=\left(K_{3-a x}^{-1}+K_{2-a x}^{-1}\right)^{-1}$. The lowest measured stiffness in $\mathrm{x}$ and $\mathrm{y}$ direction from Table 7 and Table 8 was used. The error (Err.) and standard deviation (SD.) was combined with equation 3.

\begin{tabular}{|cc|ccc|}
\hline $\mathbf{P}_{\mathbf{C N C}}+\mathbf{P}_{\mathbf{T}}$ & D. & $\begin{array}{c}\mathbf{K}_{\text {avg }} \\
\mathrm{N} / \mu \mathrm{m}\end{array}$ & $\begin{array}{c}\text { SD. } \\
\mathbf{\%}\end{array}$ & $\begin{array}{c}\mathbf{E r r} \\
\mathbf{\%}\end{array}$ \\
\hline $7+2$ & $x$ & 8.3 & 4.3 & 6.0 \\
$1+4$ & $y$ & 5.3 & 1.5 & 6.4 \\
$9+5$ & $z$ & 16.9 & 7.0 & 8.9 \\
\hline
\end{tabular}

Table 10: Approximate 5-axis stiffness: combination of 3-axis CNC stiffness (test 1.3) and 2-axis trunnion stiffness, in $x, y$ and $z$-direction.

\subsection{6-DOF Industrial Robot}

Lastly, the results from the last test subject, the 6DOF industrial robot, are presented below. The measurements was performed with the Leica AT960 laser tracker and ATI Axia80 force/torque sensor, which also provided synchronised data. The stiffness was then approximated by the same least square method as the two previous tests. While the laser tracker measures deflection along all three axes, the total vector magnitude was used.
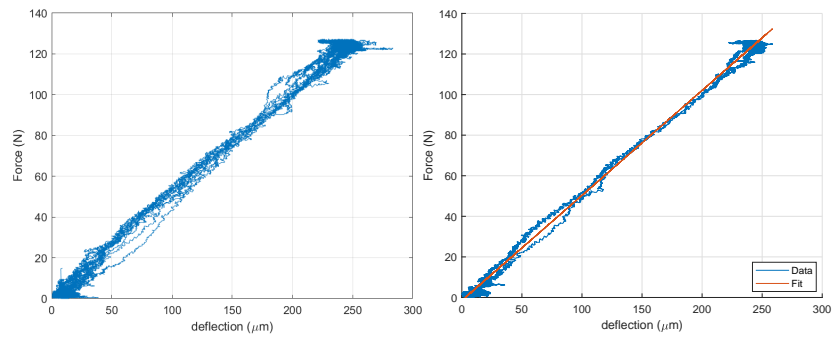

Figure 22: 6-DOF Industrial Robot: Force versus deflection. Load in y-direction with $220 \mathrm{~mm}$ pneumatic cylinder. All load cycles (L), single load cycle with least square fit $(R)$
The force was applied with the load cycles presented Figure 23. An example of the force vs deflection data and the fit to one of the load cycles are presented in Fig. 22.

The stiffness was measured at three lengths of the cylinder where the stiffness presented in Fig. 24, was found. Values presented within brackets are the stiffness when the brakes are engaged on all joints. The results are also presented in Table 11 for the points in Fig. 12. From these results, it is seen that the brakes have little impact on the stiffness of the robot. The largest difference was measured to be an increase of $\approx 15 \%$, which suggests that the servo stiffness is not as crucial as other components such as the gearbox and link stiffness.

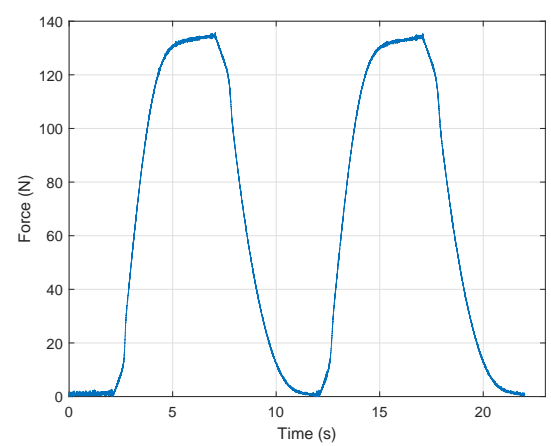

Figure 23: 6-DOF Industrial Robot: two force application cycles.

\begin{tabular}{|c|c|c|c|c|c|c|}
\hline \multirow{2}{*}{ P. } & \multicolumn{3}{|c|}{ Servo active } & \multicolumn{3}{c|}{ Brake active } \\
\cline { 2 - 7 } & $\begin{array}{c}\mathbf{K}_{\text {avg }} \\
\text { N/pm }\end{array}$ & $\begin{array}{c}\text { SD. } \\
\text { \% }\end{array}$ & $\begin{array}{c}\text { Err. } \\
\text { \% }\end{array}$ & $\begin{array}{c}\mathbf{K}_{\text {avg }} \\
\text { N/pm }\end{array}$ & $\begin{array}{c}\text { SD. } \\
\text { \% }\end{array}$ & $\begin{array}{c}\text { Err. } \\
\text { \% }\end{array}$ \\
\hline 1 & 0.52 & 0.4 & 8.2 & 0.56 & 2.2 & 7.7 \\
2 & 0.33 & 0.5 & 7.1 & 0.35 & 1.4 & 7.5 \\
3 & 0.28 & 0.1 & 6.9 & 0.30 & 0.3 & 7.3 \\
4 & 0.31 & 1.2 & 7.1 & 0.33 & 0.7 & 7.4 \\
5 & 0.54 & 1.2 & 7.4 & 0.55 & 0.7 & 7.7 \\
6 & 0.27 & 1.0 & 7.0 & 0.29 & 0.9 & 7.4 \\
7 & 0.31 & 0.7 & 6.9 & 0.33 & 0.3 & 7.3 \\
8 & 1.03 & 0.9 & 9.1 & 1.08 & 1.9 & 8.6 \\
\hline
\end{tabular}

Table 11: 6-DOF Industrial Robot: average stiffness at locations in Fig. 12 with and without brakes enabled. 


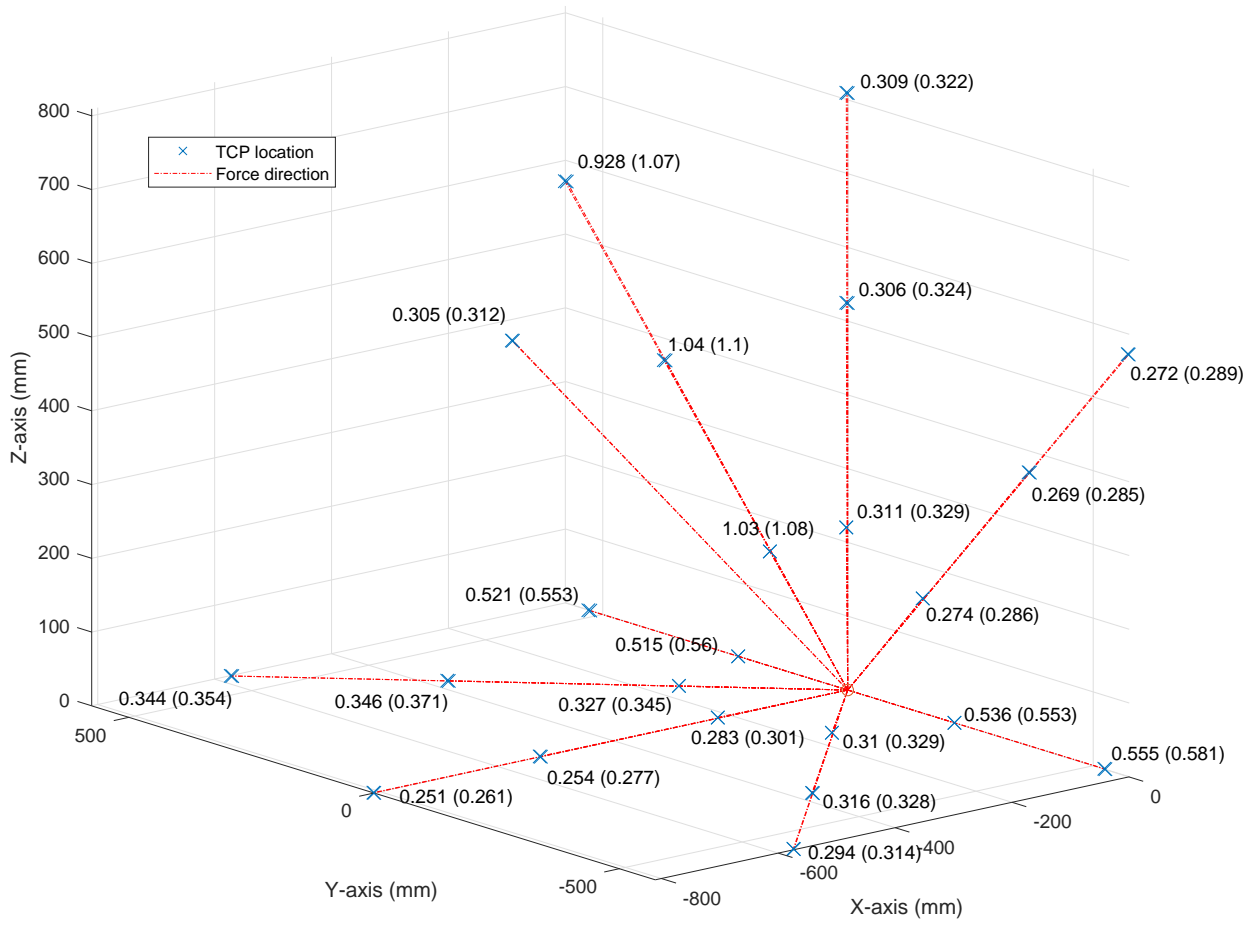

Figure 24: 6-DOF Industrial Robot: Stiffness at different TCP locations. With active servos and (active brakes). $220 \mathrm{~mm}, 525 \mathrm{~mm}$ and $810 \mathrm{~mm}$ radius sphere.

\section{Discussion}

Stiffness values of the machines that were tested in this paper are considered to be sensitive information. The choice was therefore made to not disclose the make and model of the machine and instead present the actual measured stiffness values.

The torque sensing capabilities of the sensors used in this project were not strictly necessary. The two sensors were only borrowed for the duration of the experiments as these are also used for other applications. A 3 -axis force sensor could then have been used instead, which might be more cost effective. Further simplification could be made by using a 1-axis force sensor mounted directly to the pneumatic cylinder.

The Leica laser tracker has better overall specifications than the older model of the Faro tracker which was available. It might, therefore, seem odd that the Leica tracker was not used for the first test, on the 3axis CNC. This is simply because it was not available at the time that these tests where conducted. While the 3 -axis accuracy is better it is still not considered to be good enough for determining the stiffness of the CNC. The test method that incorporated the tracker, was also limited by the fact that the measurements had to be made in two operations. The tests were therefore not repeated once the Leica laser tracker was available.
There are LVDT sensors which are more accurate and linear than the one used in this project. If a more linear sensor were to be used, the nonlinearity compensation might not be necessary. The sensor was also not new but was considered to be in good condition.

The magnetic foot was used to hold the dial indicator and the LVDT with the assumption that the 3-axis CNC table was much stiffer than the rest of the machine. This assumes that there is neglectable bending or twisting of the table between where the force sensor was mounted and the magnetic foot was positioned.

When the accuracy of the measurements were estimated, operator errors were not included. Operator errors can include errors such as the following. First is alignment error of the measurement probe, relevant to the use of the LVDT and the dial gauge. The error is typically referred to as cosine error where the measured deflection is higher than the actual deflection. Second is the aliment error of the pneumatic cylinder (direction of applied force) which gives lower force in the measured direction than what is measured by the force sensor. In the first and last test subject, the equipment was aligned by the $\mathrm{CNC}$ and the robot, which are considered to give neglectable error. The second test, on the 2-axis trunnion, the pneumatic cylinder had to be aligned by sight using straight edges and levels. It is estimated that these were aligned within 3 degrees, at 
worst, which gives cosine error of $<0.14 \%$. The cosine error is single sided only (i.e. either positive or negative), therefore, any error with the alignment will underestimate the stiffness.

The temperature of the environment was not accounted for, except for both of the laser trackers, which had an inbuilt temperature sensor and error compensation. The LVDT was, however, calibrated at the same room temperature that the tests were conducted at. Thermal disturbance of the gauge blocks is seen as insignificant at the small measurements of $<1000 \mu \mathrm{m}$.

The measurements of the 3 -axis CNC were performed in a spherical pattern with the force sensor at one location, which was at the centre of the table. While the sensor could have been re-positioned to different locations, it would have been a time-consuming process. It was therefore determined that it was better to spend time with analysing more points of the single location. It is, however, important to then notice that these measurements not only represent a change in load direction but also change in spindle position.

The results from the three different measurement methods on the 3 -axis CNC differed significantly. One certain contribution to the difference is the fact that not all parts of the measurements were performed on the same reference point. The laser tracker measurements did not include the stiffness of the tool holder and spindle, which was also the case for the dial indicator measurements in the z-direction. Also, the force sensor was positioned at a different position for the first two and the last test.

The measurements with the FARO laser tracker and digital dial indicator had a theoretical error which was greater than the measured stiffness. These two tests can therefore not be said to be conclusive. Out of the three methods, the last, using the LVDT and the smaller force sensor, is considered to be closest to the true value. The measurements using the LVDT was made on the tool holder and not on the ball joint where the load was applied. Deflection was measured at this point in order to avoid including the stiffness of the ball joint. It was then assumed that there where neglectable torsional deflection of the spindle head and tool holder.

When the brakes are engaged, the stiffness of the 2-axis trunnion is higher at position 4, with the load offset, then at position 3, which seems somewhat contradicting. The most likely explanation is that when the load point is offset from the centre of the B-axis, it is closer to the supporting bearing of the trunnion. The bending and twisting loads that the trunnion structure is subjected to is then reduced, which is presumably more critical.
The 6-DOF industrial robot was only tested at a single type of configuration, which was with no tool rotation around the z-axis. The configuration was chosen since all of the measurement locations could be reached with a single configuration. It is likely that this is not the optimal configuration of the robot in terms of stiffness. The stiffness of the spindle bearings or the tool holder were also not included, as the holder for the reflector was mounted to the body of the spindle. Since the laser tracker was positioned on the floor, the stiffness of the work table was not included either.

None of the tests included the stiffness of a tool or any work-holding, which was done on purpose since tooling is considered to be job specific. It is then important to notice that these values only represent the stiffness of the machine and that any tool or workholding will reduce the stiffness to a varying degree.

\section{Conclusion}

This paper presents results from different methods of measuring static stiffness. Some of the difficulties of measuring stiffness in precision multi-axis machining centre are highlighted, where accuracy and setup time have been the main challenge.

The importance of considering the accuracy of both the force and deflection measurement device is highlighted. From the results, its observed that high measurement precision can be achieved even if the accuracy is low.

At the load levels used in the tests, the LVDT was found to be the most promising method to provide consistent and accurate results for high stiffness machines. The method of using a laser tracker had the advantage of shorter setup and execution time. However, it is considered to be only applicable to machines with lower stiffness and with a large open workspace that the tracker can be placed on, such as industrial robots.

Not considering the stiffness of components such as a workpiece, work holding or tool, the following stiffness was measured. Lowest stiffness of the 3 -axis CNC was measured to be between $14.8 \mathrm{~N} / \mu \mathrm{m}$ and $21.1 \mathrm{~N} / \mu \mathrm{m}$ in the xy-plane and $24.7 \mathrm{~N} / \mu \mathrm{m}$ in the $\mathrm{z}$ direction. The 2 axis trunnion was measured to be as low as $7.4 \mathrm{~N} / \mu \mathrm{m}$ xy-plane (relative to the 3 -axis machine) and as high as $68.8 \mathrm{~N} / \mu \mathrm{m}$ in the $\mathrm{z}$-direction. 5-axis stiffness, with the combination of the trunnion and the CNC was approximated to be from $5.3 \mathrm{~N} / \mu \mathrm{m}$ to $16.9 \mathrm{~N} / \mu \mathrm{m}$. The 6 -DOF industrial robot was measured to have a stiffness between $0.25 \mathrm{~N} / \mu \mathrm{m}$ and $1.10 \mathrm{~N} / \mu \mathrm{m}$. 


\section{Acknowledgements}

The authors are grateful for the contributions given by Dr. Torgny Brogårdh.

\section{References}

Archenti, A., Nicolescu, M., Casterman, G., and Hjelm, S. A new method for circular testing of machine tools under loaded condition. CIRP Conference on High Performance Cutting, 2012. 1(5):575580. doi:doi.org/10.1016/j.procir.2012.05.002.

ATI Industrial Automation. F/t sensor: Axia80. https://goo.gl/1Hq6Hg, 2018a.

ATI Industrial Automation. F/t sensor: Omega160. https://goo.gl/B2a5rV, 2018b.

FARO. Product brochure - faro xi laser tracker. https : //goo.gl/yhJ3r9, 2009.

Hexagon. Product brochure - leica absolute tracker at960. https://goo.gl/n2n7Ff, 2015.

Stejskal, T., Svetlík, J., Dovica, M., Demeč, P., and Krá, J. Measurement of static stiffness after motion on a three-axis cnc milling table. Applied Sciences, 2018. 8(1). URL http://www.mdpi.com/ 2076-3417/8/1/15, doi:10.3390/app8010015.

Xianming, G., Baotong, L., Jun, H., and Junkang, G. Stiffness modeling of machine tools based on machining space analysis. The International Journal of Advanced Manufacturing Technology, 2016. 86(5):20932106. doi:10.1007/s00170-015-8336-z. 